\title{
Study on Radical Chemistry of Monoperoxycarbonates by $\alpha$-Methylstyrene Dimer Trapping Technique
}

\author{
Yasumasa Watanabe, ${ }^{\dagger}$ Hideyo Ishigaki, Hiroshi OKada, \\ and Shuji SuYama
}

Fine Chemicals \& Polymers Research Laboratory, NOF Corporation,

Taketoyo-cho, Chita-gun, Aichi 470-23, Japan

(Received June 19, 1997)

\begin{abstract}
The initiation mechanisms of $O O$ - $t$-butyl $O$-isopropyl peroxycarbonate (BuI) and $O O$ - $t$-hexyl $O$-isopropyl peroxycarbonate (HexI) were studied at $140^{\circ} \mathrm{C}$ by $\alpha$-methylstyrene dimer (MSD) trapping. Alkoxycarbonyloxy radicals (carbonate radicals) produced from the peroxides were trapped by MSD almost quantitatively, indicating that decarboxylation of carbonate radicals was too slow to compete with addition to the styreneic double bond even at high temperature. The hydrogen abstraction ability of these peroxides was evaluated in a mixture of MSD and cyclohexane. Hydrogen abstraction ability of HexI was much lower than that of BuI. In bulk styrene polymerization, BuI acted as a more efficient initiator than the perester type initiator of $t$-butyl peroxylaurate, keeping high initiator efficiency up to high monomer conversions.
\end{abstract}

KEY WORDS Radical Trapping/Monoperoxycarbonates/Initiation Mechanism/Decarboxylation / Hydrogen Abstraction / Initiator Efficiency /

Monoperoxycarbonates are useful initiators for styrene polymerization and used at relatively high temperatures above $100^{\circ} \mathrm{C}$. The homolytic cleavage of the $\mathrm{O}-\mathrm{O}$ bond gives alkoxy and alkoxycarbonyloxy (carbonate) radicals. While much information on the reactions of alkoxy radicals is available, ${ }^{1,2}$ information on carbonate radicals is quite limited, ${ }^{3-5}$ particularly at high temperature. Recently, Chateauneuf et al. ${ }^{5}$ determined the absolute rate constants for reactions of carbonate radicals by laser flash photolysis technique. For $n$-propoxycarbonyloxy radicals ( $n$-PrOCOO $\cdot$ ), the rate constants for the addition to styrene, hydrogen abstraction from cyclohexane, and decarboxylation were reported to be $2.0 \times 10^{9}$ $\mathrm{M}^{-1} \mathrm{~s}^{-1}, 1.6 \times 10^{7} \mathrm{M}^{-1} \mathrm{~s}^{-1}$, and $\leqq 1.6 \times 10^{5} \mathrm{~s}^{-1}$, respectively, in $\mathrm{CCl}_{4}$ at $20^{\circ} \mathrm{C}$. This indicates that decarboxylation of carbonate radicals can not compete with addition to styrene at low temperature. However, the reactivity of radicals should be greatly dependent on reaction temperature. To obtain useful information, it is worthwhile to investigate carbonate radical reactivity at high temperature.

We developed a new method for investigating the initiation mechanisms of organic peroxides using 2,4diphenyl-4-methyl-1-pentene ( $\alpha$-methylstyrene dimer, MSD) as a radical trapping agent. ${ }^{6}$ This technique is based on the unique radical chemistry of MSD, that is, addition-fragmentation reactions between free radicals and MSD (eq 1 and 2). ${ }^{7}$ Cumyl radicals ejected from MSD are deactivated by self-reactions (eq 3 ).

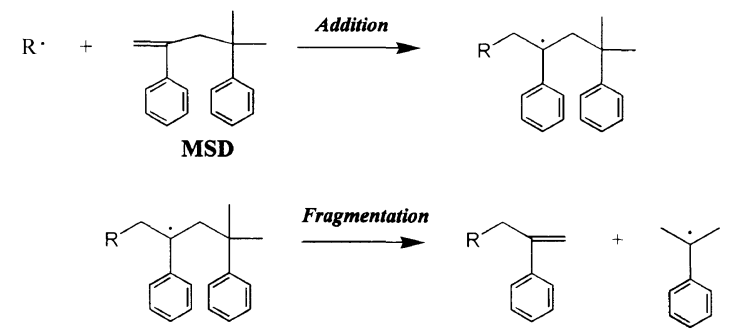

\footnotetext{
† To whom all correspondence should be addressed.
}

MSD trapping is outlined in Scheme 1. When organic peroxides decompose in MSD, olefinic compounds (1) having various fragments $(\mathrm{X})$ derived from organic peroxides are produced through addition-fragmentation reactions. By analyzing the trapping products (1), we obtain useful information on the free radical chemistry of organic peroxides. We demonstrated that the double bond reactivity of MSD is about the same as that of styrene. ${ }^{6}$ Therefore, the trapping products are closely related to initiating radicals in styrene polymerization.

We also developed a new method for evaluating hydrogen abstraction ( $\mathrm{H}$-abstraction) ability of organic peroxides using MSD trapping (Scheme 2). ${ }^{8}$ When organic peroxides are decomposed in a mixture of MSD and cyclohexane, cyclohexyl radicals produced through $\mathrm{H}$-abstraction by peroxide-derived radicals from cyclohexane are trapped by MSD. The yield of cyclohexyl radical trapping product (2) is regarded as $\mathrm{H}$-abstraction ability of organic peroxides in the presence of styrenic monomers.

MSD trapping is applicable even at high temperature. Thus, it is expected that the reactivity of carbonate

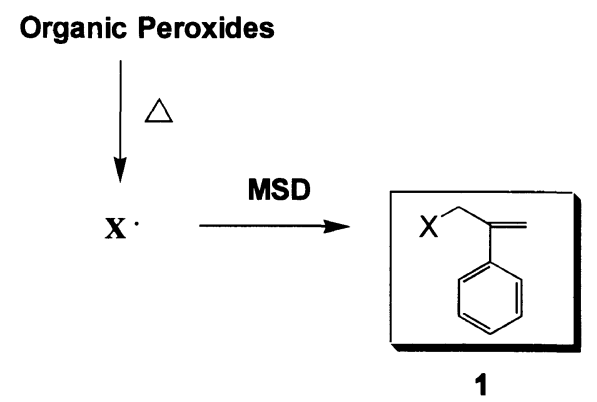

Scheme 1. Outline of MSD trapping. 


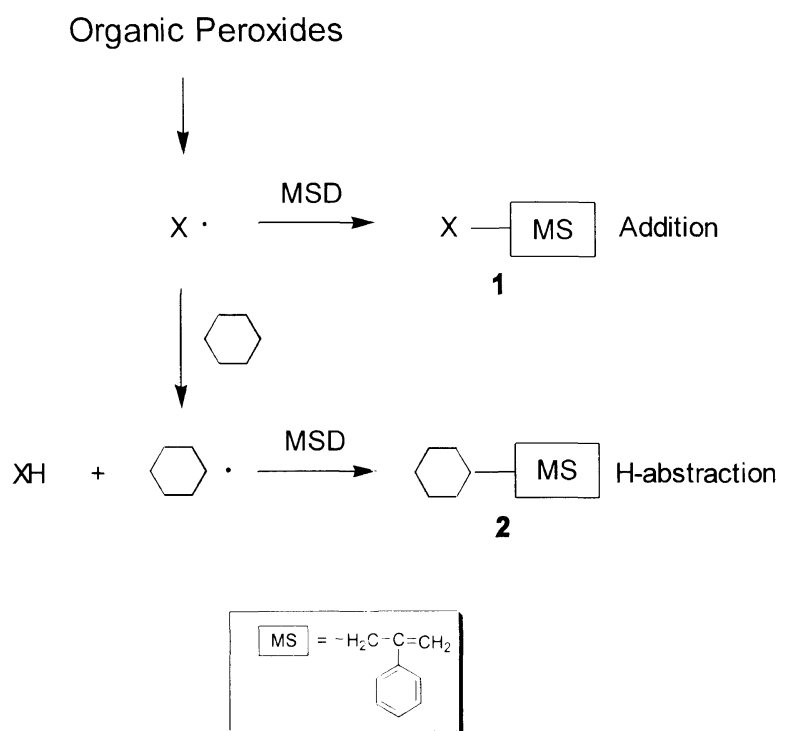

Scheme 2. Method for evaluating H-abstraction ability of organic peroxides.

radicals at high temperature can be easily studied via thermolysis of monoperoxycarbonates in the presence of MSD. This paper describes the initiation mechanisms and hydrogen abstraction ability of useful monoperoxycarbonate initiators, $O O$ - $t$-butyl $O$-isopropyl peroxycarbonate $(\mathrm{BuI})$ and $O O-t$-hexyl $O$-isopropyl peroxycarbonate (HexI), by MSD trapping at $140^{\circ} \mathrm{C}$, and initiation performance of $\mathrm{BuI}$ in bulk styrene polymerization is presented in comparison with a perester-type initiator.

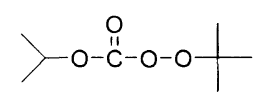

Bul

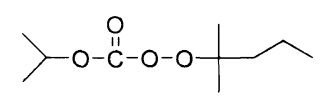

Hexl

\section{EXPERIMENTAL}

\section{Measurements}

GLC analysis was performed with Shimadzu GC-14A and GC-17A gas chromatographs with a flame ionization detector using capillary columns $(15 \mathrm{~m} \times 0.53 \mathrm{~mm}$ or $25 \mathrm{~m} \times 0.25 \mathrm{~mm}$ ). GC-MS analysis was conducted on a Shimadzu QP5000 under electron impact conditions $(70 \mathrm{eV})$.

\section{Materials}

MSD was obtained from NOF Corporation (Nofmer MSD) and used after purification by distillation. BuI, HexI, $t$-butyl peroxylaurate (BuL), $t$-butyl peroxybenzoate (BuZ), and $t$-hexyl peroxybenzoate (HexZ) were used as received from NOF Corporation (purity: $98.0,90.4,98.2,98.6$, and $96.2 \%$, respectively).

Commercial grade styrene was washed with $2 \% \mathrm{NaOH}$ and water, and distilled under reduced pressure before use. Cyclohexane was of guaranteed reagent grade.

\section{MSD Trapping Experiments}

An aliquot $(2 \mathrm{ml})$ of a $0.02 \mathrm{M}$ solution of BuI or HexI in MSD was charged into a glass ampoule, which was purged with nitrogen, sealed and immersed in a constant temperature bath at $140^{\circ} \mathrm{C}$ for $5 \mathrm{~h}$. The reaction products were analyzed by GLC and GC-MS. Typical conditions of GLC analysis were as follows: column, $25 \mathrm{~m} \times 0.25 \mathrm{~mm}$ capillary column of silicon OV-1 (Shimadzu, HR-1); injector temperature, $150^{\circ} \mathrm{C}$; detector temperature, $250^{\circ} \mathrm{C}$; initial oven temperature, $50^{\circ} \mathrm{C}$; initial hold, $10 \mathrm{~min}$; program rate $1,10^{\circ} \mathrm{C} \mathrm{min}^{-1}$; middle oven temperature, $150^{\circ} \mathrm{C}$; middle hold, $10 \mathrm{~min}$; program rate $2,10^{\circ} \mathrm{C} \mathrm{min}^{-1}$; final oven temperature, $250^{\circ} \mathrm{C}$; final hold, $10 \mathrm{~min}$; carrier gas, $\mathrm{He}\left(0.4 \mathrm{ml} \mathrm{min}^{-1}\right)$; split ratio, $1: 18$.

GC retention times and MS spectra of trapping products are given below. The MS spectra showed characteristic fragment peaks of 117, 103,91, and 77 due to the 2-phenylallyl group of MSD.

Isopropyl 2-phenyl-2-propenyl carbonate (1a). GC retention time, $34.7 \mathrm{~min}$; MS $(70 \mathrm{eV}) \mathrm{m} / z 220\left(\mathrm{M}^{+}\right), 178$, $134,117,115,105,103,91,77$, and 43.

3-t-Butoxy-2-phenyl-1-propene (1b). GC retention time, $27.9 \mathrm{~min}$; MS $(70 \mathrm{eV}) \mathrm{m} / \mathrm{z} 190\left(\mathrm{M}^{+}\right), 175,145,134,117$, $103,92,91,77,57$, and 41 .

2-Phenyl-l-butene (1c). GC retention time, $18.9 \mathrm{~min}$; MS $(70 \mathrm{eV}) m / z 132\left(\mathrm{M}^{+}\right), 117,103,91,77,54$, and 51.

2-Phenyl-1-hexene (1d). GC retention time, $23.2 \mathrm{~min}$; MS (70 eV) $m / z 160\left(\mathrm{M}^{+}\right), 145,131,118,117,103,91$, $78,77,65,51$.

7-Hydroxy-7-methyl-2-phenyl-1-octene (1e). GC retention time, $38.0 \mathrm{~min}$; $\mathrm{MS}(70 \mathrm{eV}) \mathrm{m} / z 200\left(\mathrm{M}^{+}-\mathrm{H}_{2} \mathrm{O}\right)$, $185,157,144,131,129,118,117,105,103,91,77,59$, and 43.

3-Cyclohexyl-2-phenyl-1-propene (2). GC retention time, $36.1 \mathrm{~min}$; MS (70 eV) $\mathrm{m} / \mathrm{z} 200\left(\mathrm{M}^{+}\right), 185,157,143$, $118,117,103,91,77,55$, and 41 .

\section{Polymerization of Styrene}

The radical polymerization of styrene was carried out in the presence of $2 \mathrm{mM} \mathrm{BuI}$ or BuL in bulk at $120^{\circ} \mathrm{C}$ in a sealed glass ampoule purged with nitrogen. Percentage conversion was obtained from residual monomer analysis by GLC.

\section{RESULTS AND DISCUSSION}

\section{MSD Trapping}

The thermal decomposition of BuI and HexI was carried out in MSD at $140^{\circ} \mathrm{C}$ for $5 \mathrm{~h}$ under nitrogen. Decomposition percentages were over $99.9 \%$. MSD trapping products were confirmed by GLC and GC-MS. GLC yields of trapping products based on total radicals produced theoretically from peroxides $(2 \mathrm{~mol}$ of radicals per mol of peroxides) and possible schemes leading to their production are shown in Schemes 3 and 4.

Total trapping yields for BuI and HexI were 79 and $88 \%$, respectively. The somewhat lower yield of BuI was due to the small recovery of the $t$-butoxy moiety. In the case of BuI, a small amount of $t$-butylalcohol $(10 \%)$ was detected. This indicates hydrogen abstraction by $t$-butoxy radicals to occur. Thus, the actual free radical production efficiency of BuI should be almost the same as that of HexI and close to unity. Possibly, hydrogen abstraction occurs at allylic hydrogens of MSD (eq 4), since allylic hydrogens are easily abstracted by alkoxy radicals. ${ }^{9}$ The reactions of $t$-butoxy radicals with $\alpha$-methylstyrene at $60^{\circ} \mathrm{C}$ lead to $15 \%$ hydrogen abstraction from allylic hydrogens $\left(85 \%\right.$ addition to the double bond). ${ }^{10}$ 

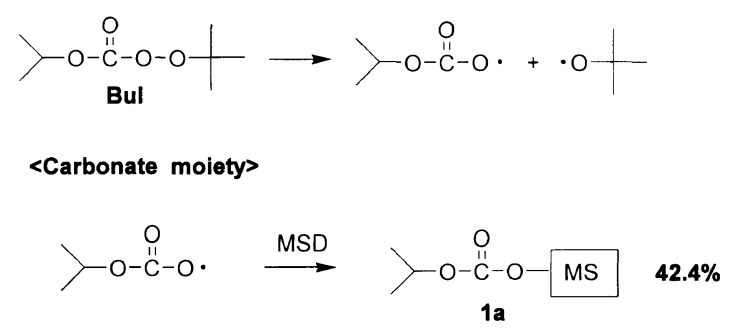

<Alkoxy moiety>

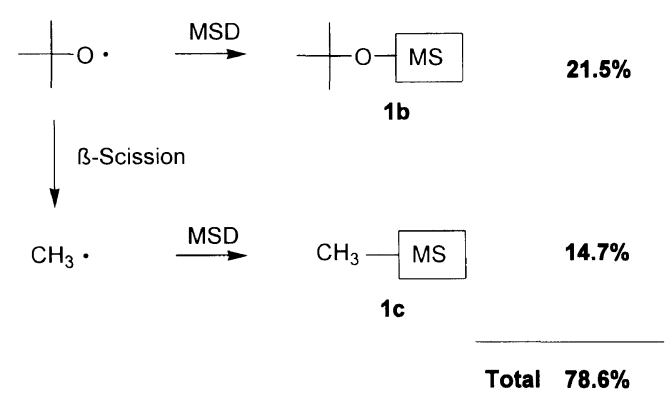

Scheme 3. Initiation mechanism of BuI at $140^{\circ} \mathrm{C}$.

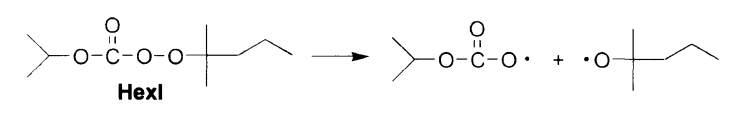

<Carbonate moiety>

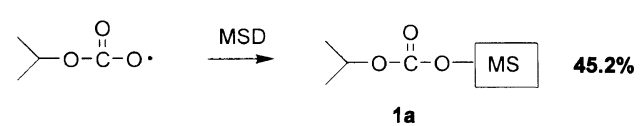

<Alkoxy moiety>

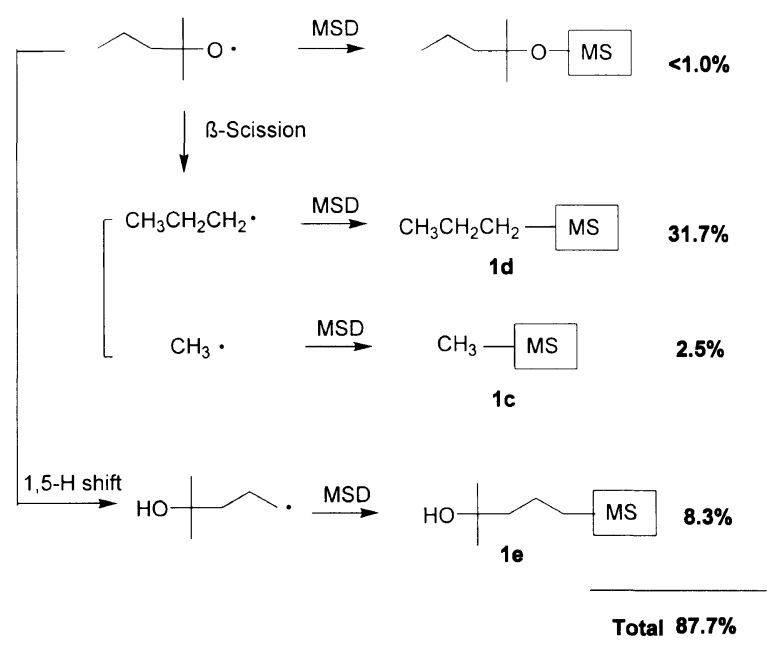

Scheme 4. Initiation mechanism of $\mathrm{HexI}$ at $140^{\circ} \mathrm{C}$.

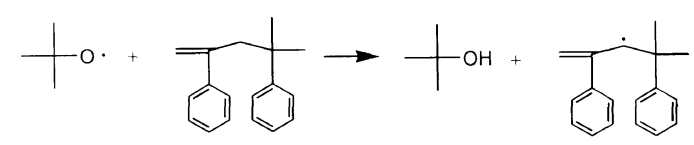

Carbonate radicals were efficiently trapped by MSD in both cases. If carbonate radicals undergo decarboxylation, isopropoxy radicals should be trapped by MSD (eq 5). However, such trapping could not be detected. These results clearly demonstrate that decarboxylation of carbonate radicals is very slow even at high temperature $\left(140^{\circ} \mathrm{C}\right)$ and can not compete with addition to the styrenic double bond.

$$
>\mathrm{O}-\mathrm{O}-\mathrm{C}-\mathrm{O} \cdot \stackrel{-\mathrm{CO}_{2}}{\longrightarrow}>\mathrm{O} \cdot \stackrel{\mathrm{MSD}}{\longrightarrow}>-\mathrm{O}-\mathrm{MS}
$$

A previous study of the initiation mechanisms of peresters, $\mathrm{BuL}$ and $\mathrm{BuZ}$, in $\mathrm{MSD}$ at $140^{\circ} \mathrm{C}$ showed that lauroyloxy radicals undergo $100 \%$ decarboxylation, while benzoyloxy radicals undergo $29 \%$ decarboxylation and $71 \%$ addition to MSD. ${ }^{11}$ Thus, it is summarized that decarboxylation rates at $140^{\circ} \mathrm{C}$ decrease in the following order: aliphatic acyloxy radicals $\gg$ aromatic acyloxy radicals $>$ carbonate radicals. This order is consistent with that studied at low temperature. The absolute rate constants for decarboxylation at $c a .20^{\circ} \mathrm{C}$ are reported to be $\sim 10^{9}-10^{10}, \sim 10^{6}$, and $\leqq 10^{5} \mathrm{~s}^{-1}$, respectively. ${ }^{5,12}$ This rate difference in decarboxylation rates can be reasonably explained due to differences in stability of radicals formed after decarboxylation, i.e., alkyl $\gg$ aryl $>$ alkoxy.

Various reactions were observed for alkoxy radicals, depending on structure. For $t$-butoxy radicals, addition and $\beta$-scission occurred with a ratio of 59/41. $\beta$-Scission (elimination of $n$-propyl radicals) and 1,5-hydrogen shift (1,5-H shift) were major reactions for $t$-hexyloxy radicals, the ratio of $\beta$-scission to $1,5-\mathrm{H}$ shift being $79 / 21$. Previously, we reported the initiation reactions of alkoxy radicals under the same conditions (in MSD at $140^{\circ} \mathrm{C}$ ), where dialkyl peroxides such as di-t-butyl peroxide $(\mathrm{BuD})$ and di- $t$-hexyl peroxide (HexD) were used as generators of alkoxy radicals. ${ }^{6}$ The addition $/ \beta$-scission ratio for $t$-butoxy radicals was $62 / 38$, and $n$-propyl elimination/ $1,5-\mathrm{H}$ shift ratio for $t$-hexyloxy radicals, $79 / 21$. These ratios are in good agreement with those obtained in this study.

\section{Hydrogen Abstraction Ability}

First, H-abstraction ability of BuI and HexI was evaluated by the conventional method (dimer method) measuring dehydrodimers of solvents when organic peroxides are decomposed in a solvent. The thermal decomposition of BuI and HexI was carried out in neat cyclohexane at $150^{\circ} \mathrm{C}$. The yield of cyclohexane dimer (dicyclohexyl) was determined by GLC. The results are shown in Table I. There was no significant difference in dimer yields for BuI and HexI, and dimer yields were nearly equal to those of dialkyl peroxides (BuD and HexD). ${ }^{8}$ Since bimolecular self-reactions of cyclohexyl radicals occur by coupling and disproportionation at around $50 / 50,{ }^{13}$ the maximum dimer yield is about $50 \%$. Thus, it was found that the radicals generated from monoperoxycarbonates efficiently abstract hydrogen in neat cyclohexane.

$\mathrm{H}$-Abstraction ability of BuI and HexI was evaluated in a mixture of MSD $(2.0 \mathrm{M})$ and cyclohexane $(4.7 \mathrm{M})$ at $140^{\circ} \mathrm{C}$ according to the method in Scheme 2. The results were compared with those for dialkyl peroxides and peresters (Table II). H-Abstraction ability for BuI and HexI differed considerably $(\mathrm{BuI}>\mathrm{HexI})$. The lower $\mathrm{H}$-abstraction ability of $t$-hexyl-derived peroxide is consistent with the results for dialkyl peroxides $(\mathrm{BuD}>$ $\mathrm{HexD})^{8}$ and peresters $(\mathrm{BuZ}>\mathrm{HexZ})$, due to the faster self-reaction ( $\beta$-scission and 1,5-shift) of $t$-hexyloxy 
Table I. Yields of dicyclohexyl from the decomposition of BuI and HexI in cyclohexane at $150^{\circ} \mathrm{C}^{\text {a }}$

\begin{tabular}{lc}
\hline & Yield of dicyclohexyl $^{\mathrm{b}}$ \\
\cline { 2 - 2 } Peroxide & $\%$ \\
\hline $\mathrm{BuI}$ & 42 \\
$\mathrm{HexI}$ & 41 \\
$\mathrm{BuD}^{\mathrm{c}}$ & $42^{\mathrm{d}}$ \\
$\mathrm{HexD}^{\mathrm{e}}$ & $44^{\mathrm{d}}$ \\
\hline
\end{tabular}

a Initial peroxide concentration, $0.01 \mathrm{M}$; decomposition percentages, $>99.9 \%$. ${ }^{\text {b }}$ Based on peroxides. ${ }^{\mathrm{c}}$ Di- $t$-butyl peroxide. ${ }^{\mathrm{d}}$ Data from ref 8. ${ }^{\mathrm{e}}$ Di-t-hexyl peroxide.

Table II. Yields of cyclohexyl trapping product (2) from the decomposition of BuI and HexI in a mixture of MSD and cyclohexane at $140^{\circ} \mathrm{C}^{\mathrm{a}}$

\begin{tabular}{lc}
\hline & Yield of $\mathbf{2}^{\mathrm{b}}$ \\
\cline { 2 - 2 } & $\%$ \\
\hline BuI & 43 \\
HexI & 15 \\
BuZ & 46 \\
HexZ & 19 \\
BuL & 29 \\
BuD & $72^{\mathrm{f}}$ \\
HexD & $14^{\mathrm{f}}$
\end{tabular}

a Initial peroxide concentration, $0.02 \mathrm{M}$; decomposition percentages, $>99.9 \%$; MSD, $2.0 \mathrm{M}$; cyclohexane, $4.7 \mathrm{M} .{ }^{\mathrm{b}} 100 \times(\mathrm{mol}$ of $\mathbf{2} /$ half $\mathrm{mol}$ of peroxides). ${ }^{\mathrm{c}} t$-Butyl peroxybenzoate. ${ }^{\mathrm{d}} t$-Hexyl peroxybenzoate. ${ }^{\mathrm{e}} t$-Butyl peroxylaurate. ${ }^{\mathrm{f}}$ Data from ref 8 .

radicals to give alkyl radicals. Alkyl radicals are poor hydrogen abstractors and readily trapped by MSD before abstracting hydrogen from cyclohexane.

The yield of $\mathbf{2}$ for BuI is only slightly higher than half of that for $\mathrm{BuD}$, clearly demonstrating that carbonate radicals are little involved in hydrogen abstraction in the presence of MSD and much more active in addition to the styrenic double bond of MSD. For $n$-PrOCOO $\cdot$, the rate constant for addition to styrene $\left(2.0 \times 10^{9} \mathrm{M}^{-1} \mathrm{~s}^{-1}\right)$ was reported to be about 100 times that for hydrogen abstraction from cyclohexane $\left(1.6 \times 10^{7} \mathrm{M}^{-1} \mathrm{~s}^{-1}\right)$ in $\mathrm{CCl}_{4}$ at $20^{\circ} \mathrm{C}$. Although a direct comparison of the present and reported results is difficult due to large differences in reaction temperatures, they are qualitatively consistent.

$\mathrm{BuL}$ is a $t$-butyl-derived peroxide, but the $\mathrm{H}$-abstraction ability was much lower than that of $\mathrm{BuI}$ and $\mathrm{BuZ}$, due to the lower free-radical production efficiency of $\mathrm{BuL}$ compared to $\mathrm{BuI}$ or $\mathrm{BuZ}$ (see below).

\section{Polymerization of Styrene}

Free-radical production efficiency of aliphatic peresters is reduced by cage reactions, that is, bimolecular radical-radical reactions between alkoxy-alkyl radical pairs (Scheme 5). ${ }^{14}$ Such reactions are caused by the facile decarboxylation of acyloxy radicals and are greatly influenced by medium viscosity (favorable at high viscosity). The present study shows that decarboxylation of carbonate radicals is very slow even at high temperature, and that free radical production efficiency of monoperoxycarbonates is close to unity in MSD. This

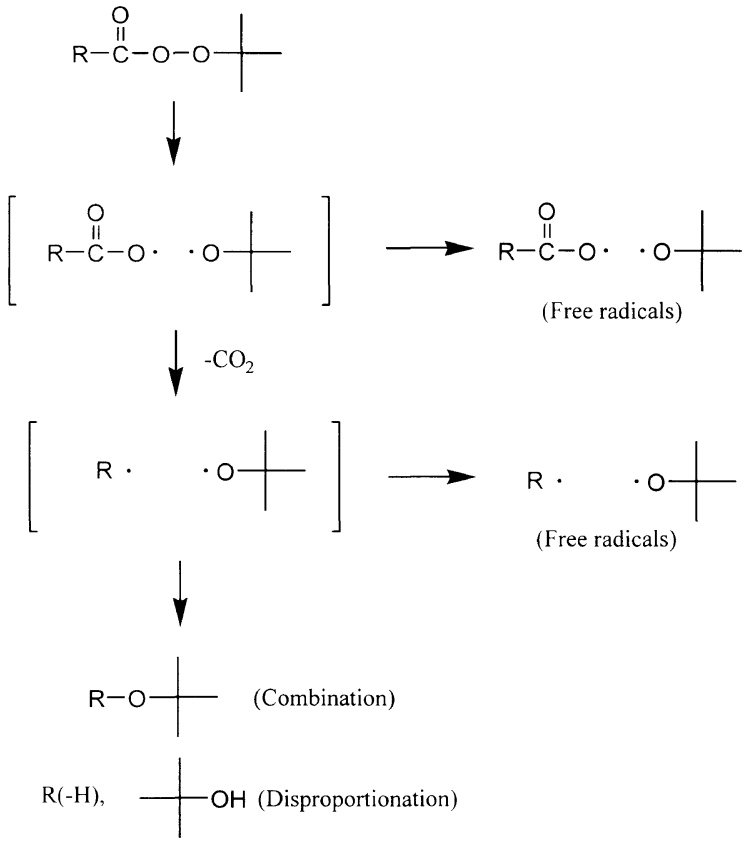

Scheme 5. Cage reactions of peresters.

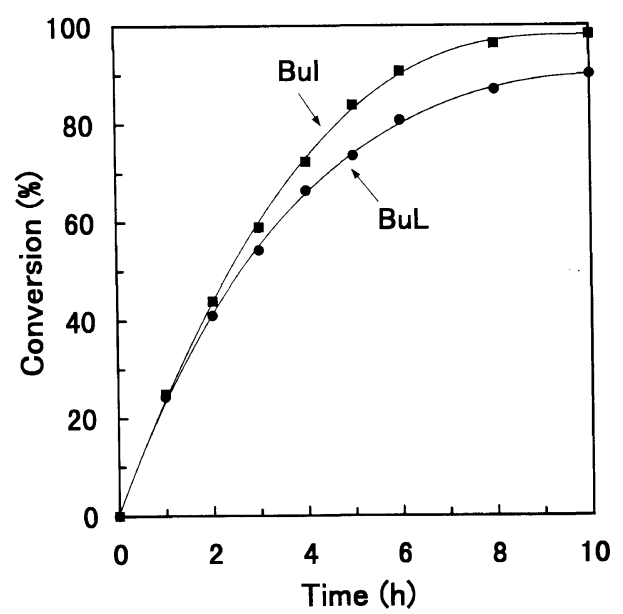

Figure 1. Time-conversion plot of bulk styrene polymerization with $\mathrm{BuI}$ or BuL at $120^{\circ} \mathrm{C}$ : [Initiator $]_{0}=2 \mathrm{mM}$.

strongly suggests that monoperoxycarbonates act as highly efficient initiators for the polymerization of styrene. To confirm this, the effectiveness of BuI for styrene polymerization was compared with that of $\mathrm{BuL}$ (aliphatic perester). Figure 1 shows the time-conversion plots of bulk styrene polymerization at $120^{\circ} \mathrm{C}$. It is clear that $\mathrm{BuI}$ is more effective than $\mathrm{BuL}$, particularly at high monomer conversions. The decomposition rate constants $\left(k_{\mathrm{d}}\right)$ of $\mathrm{BuI}$ and $\mathrm{BuL}$ were almost the same $\left(2.27 \times 10^{-4}\right.$ and $2.33 \times 10^{-4} \mathrm{~s}^{-1}$, respectively, in benzene at $120^{\circ} \mathrm{C}$ ). Therefore, it is obvious that differences in effectiveness of $\mathrm{BuI}$ and $\mathrm{BuL}$ are due to those in initiator efficiency. That is, BuI keeps efficiency up to high monomer conversion or high viscosity, due to the slow decarboxylation of carbonate radicals or absence of cage reactions.

\section{REFERENCES}

1. J. K. Kochi, in "Free Radicals," Vol. II, J. K. Kochi, Ed., John Wiley \& Sons, New York, N.Y., 1973, pp 677-695. 
2. J. A. Howard and J. C. Scaiano, in "Landolt-Börnstein. New Series. Radical Reaction Rates in Liquids," Vol. 13d, H. Fischer, Ed., Springer-Verlag, Berlin, 1984.

3. S. G. Cohen and D. B. Sparrow, J. Am. Chem. Soc., 72, 611 (1950).

4. D. E. Van Sickle, J. Org. Chem., 34, 3446 (1969).

5. J. Chateauneuf, J. Lusztyk, B. Maillard, and K. U. Ingold, $J$. Am. Chem. Soc., 110, 6727 (1988).

6. Y. Watanabe, H. Ishigaki, H. Okada, and S. Suyama, Polym. J., 29, 366 (1997).

7. Y. Watanabe, H. Ishigaki, H. Okada, and S. Suyama, Chem. Lett., 1089 (1993); S. Suyama, H. Ishigaki, Y. Watanabe, and T. Nakamura, Polym. J., 27, 371 (1995); S. Suyama, H. Ishigaki, Y. Watanabe, and T. Nakamura, Polym. J., 27, 503 (1995).

8. Y. Watanabe, H. Ishigaki, H. Okada, and S. Suyama, Polym. J., 29, 940 (1997).
9. K. U. Ingold, in "Free Radicals," Vol.I, J. K. Kochi, Ed., John Wiley \& Sons, New York, N.Y., 1973, p 74.

10. R. D. Grant, E. Rizzardo, and D. H. Solomon, Makromol. Chem., 185, 1809 (1984).

11. Y. Watanabe, H. Ishigaki, H. Okada, and S. Suyama, Polym. J., 29, 603 (1997).

12. J. Chateauneuf, J. Lusztyk, and K. U. Ingold, J. Am. Chem. Soc., 110, 2886 (1988); K. Fujimori, in "Organic Peroxides," W. Ando, Ed., John Wiley \& Sons, New York, N.Y., 1992, pp 361-367.

13. W. A. Cramer, J. Phys. Chem., 71, 1171 (1967); K. U. Ingold, in "Free Radicals," Vol. I, J. K. Kochi, Ed., John Wiley \& Sons, New York, N.Y., 1973, p 51.

14. R. A. Sheldon and J. K. Kochi, J. Am. Chem. Soc., 92, 5175 (1970); T. Koenig, in "Free Radicals," Vol. I, J. K. Kochi, Ed., John Wiley \& Sons, New York, N.Y., 1973, Chapter 3. 